\title{
RELATIONSHIP BETWEEN THE MICROSTRUCTURE, LOW CYCLE FATIGUE AND CREEP PROPERTIES OF A CAST AND WROUGHT Ni-Co BASE SUPERALLOY TMW-4M3 DISK
}

\author{
Shinichi Kobayashi ${ }^{1}$, Tomonori Ueno ${ }^{1}$, Takehiro Ohno ${ }^{1}$, Hiroshi Harada ${ }^{2}$ \\ ${ }^{1}$ Hitachi Metals, Ltd., Yasugi Works, 1240-2, Hashima-cho, Yasugi, Shimane, 692-8601, Japan \\ ${ }^{2}$ National Institute for Materials Science, 1-2-1, Sengen, Tsukuba, Ibaraki, 305-0047, Japan \\ Keywords: Ni-Co base, TMW alloy, disk, TMW-4M3, $\gamma^{\prime}$, creep, fatigue
}

\begin{abstract}
A series of cast and wrought (C\&W) Ni-Co base superalloy TMW (TMW is a trademark of National Institute for Materials Science registerd in Japan.) alloys, was developed for applications of turbine disks and other components. TMW-4M3 has excellent creep resistance among the lineup of TMW alloys. A TMW-4M3 disk with increasing amounts of strengthening elements $(\mathrm{Ti}, \mathrm{B}$ and $\mathrm{Zr}$ ) was produced via improved hot-working process, starting from an ingot of industrial triple-melt (vacuum induction melting / electro-slag remelting / vacuum arc remelting). To investigate the effect of the microstructure on fatigue and creep properties, another TMW-4M3 disk with standard composition produced by previous trial (not improved) processes and an Alloy 720 Li disk were also prepared as references. A TMW-4M3 disk via improved process had fine grains pinned by primary $\gamma^{\prime}$ particles after solution heat-treatment at $1100^{\circ} \mathrm{C}$. ALA grain size of this disk was finer than that of a previous trial disk, though average grain sizes were similar. This TMW-4M3 disk having small ALA grain exhibited long fatigue life at $400^{\circ} \mathrm{C}$ compared to other disks. In addition, creep rupture life at $725^{\circ} \mathrm{C}$ of this TMW-4M3 disk was longer than those of a previous trial disk and Alloy $720 \mathrm{Li}$ disk due to larger amounts of $\mathrm{Ti}, \mathrm{B}$ and $\mathrm{Zr}$. Therefore, these results show that this improved TMW-4M3 disk had good low cycle fatigue properties and creep resistances.
\end{abstract}

\section{Introduction}

Polycrystalline Ni-base superalloys are widely used in aircraft engines and land-based gas turbine engines. Currently, it is necessary to develop new materials meeting high requirements at elevated temperatures. Especially, alloy development for disks, which have good balance between tensile, low cycle fatigue (LCF), and creep properties at high levels, is desired.

A series of cast and wrought $(\mathrm{C} \& \mathrm{~W}) \mathrm{Ni}$-Co base superalloy TMW alloys, developed for the applications of turbine disks and other components used beyond $700^{\circ} \mathrm{C}$, has much higher creep resistance than commercial C\&W Ni-base superalloys[1]. TMW alloys were designed by mixing two kinds of $\gamma / \gamma^{\prime}$ two phase superalloys, Ni-base superalloy and Co-Ti alloy. Especially, TMW-4M3 containing $25 \mathrm{wt} \% \mathrm{Co}$ and $6.2 \mathrm{wt} \% \mathrm{Ti}$, has excellent strength among the lineup of TMW alloys[1-3]. However, it is difficult to obtain TMW-4M3 billets having satisfactorily recrystallized microstructure because this alloy does not have enough ductility for hot-working due to large amount of $\gamma^{\prime}$ precipitates. For instance, this alloy has a larger amount of $\gamma^{\prime}$ than Alloy 720Li. Difficulty in forging often leads to inhomogeneous microstructure such as non-uniform grains and un-recrystallized grains. These microstructures may lead to a decrease in mechanical properties.

The performance of C\&W TMW-4M3 as turbine components of advanced engines can be increased by combining of LCF life and creep resistance at high levels. The aim of this work is therefore to investigate the relationship between the microstructure, fatigue and creep properties and to determine optimum microstructure of this alloy for a high temperature application. In general, creep resistance can be better at large grain sizes. On the other hand, fatigue properties are good when the grain size is small[4]. Therefore, a TMW-4M3 VAR ingot containing slightly higher amount of $\mathrm{Ti}, \mathrm{B}$ and $\mathrm{Zr}$ was prepared for increasing creep resistance. The ingot was forged to billet with fine grains by improved hot-working processes which enable to reduce crack sensitivity and induce recrystallization for obtaining good fatigue strength. A TMW-4M3 billet produced by previous trial (not improved) processes and an Alloy 720Li commercial billet were also prepared as references. Alloy $720 \mathrm{Li}$ is known as one of the strongest $\mathrm{C} \& \mathrm{~W} \mathrm{Ni}$ based superalloys commercially used. Pancake disks with $440-470 \mathrm{~mm}$ in diameter were produced from these billets by hot-die forging. Microstructures and mechanical properties of these disks were investigated.

\section{Experimental Procedure}

Billet making and disk forging

TMW-4M3 ingot with $450-460 \mathrm{~mm}$ in diameter was produced through vacuum induction melting (VIM), electro-slag remelting (ESR) and vacuum arc remelting (VAR). This ingot was forged into $220 \mathrm{~mm}$ diameter billet using upset and $\operatorname{cog}$ practice below $\gamma^{\prime}$ solvus by hydraulic press. The initial forging (ingot conversion) processes generally impact on the ductility during hot-working and the uniformity of microstructure of the billet. In order to obtain the recrystallized microstructure of the billet in the early stages without heavy cracks, forging processes (upset and cog) and reheating processes were carried out at different temperatures. The initial forging and heat-treating processes from the ingot were conducted via several cycles of hot-working below $1125^{\circ} \mathrm{C}$ to introduce strain, followed by heat-treatment above forging temperature to induce recrystallization. Due to these cycles, the ingot having high crack sensitivity was made into the billet with stable ductility. After these cycles, the intermediate billet was forged into a $220 \mathrm{~mm}$ diameter billet at $1050-1120^{\circ} \mathrm{C}$ without significant cracking as shown in Fig.1.

A previous trial billet of TMW-4M3 and a commercial billet of Alloy $720 \mathrm{Li}$ made from triple-melt ingots were prepared as 
references. Chemical compositions of these billets are given in Table 1. The TMW-4M3 billet (referred to as 4M3-I) by improved billeting process contained slightly higher $\mathrm{Ti}, \mathrm{B}$, and $\mathrm{Zr}$ than standard composition[1,3]. Another previous trial billet of TMW-4M3 (referred to as 4M3-X) had similar composition to standard one. Pancake disks with 470mm (4M3-I and 720Li) and $440 \mathrm{~mm}(4 \mathrm{M} 3-\mathrm{X})$ in diameter were produced from these billets by hot-die forging at $\gamma^{\prime}$ sub-solvus temperature with no cracking.

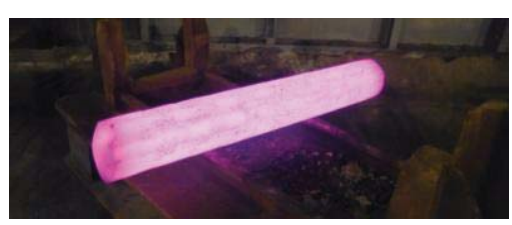

Fig.1 A 220mm diameter billet of TMW-4M3

Table 1 Chemical compositions of each alloy

\begin{tabular}{|c|c|c|c|c|c|c|c|c|c|c|}
\hline Alloy & $\mathrm{Ni}$ & $\mathrm{Cr}$ & $\mathrm{Co}$ & $\mathrm{Mo}$ & $\mathrm{W}$ & $\mathrm{Ti}$ & $\mathrm{Al}$ & $\mathrm{C}$ & $\mathrm{B}$ & $\mathrm{Zr}$ \\
\hline 4M3-I & Bal. & 13 & 24 & 2.9 & 1.1 & 6.4 & 2.4 & 0.015 & 0.027 & 0.044 \\
\hline 4M3-X & Bal. & 13 & 25 & 2.7 & 1.2 & 6.0 & 2.2 & 0.016 & 0.013 & 0.028 \\
\hline $720 \mathrm{Li}$ & Bal. & 16 & 15 & 3.0 & 1.1 & 4.9 & 2.7 & 0.015 & 0.016 & 0.029 \\
\hline
\end{tabular}

\section{$\underline{\text { Heat-treatment }}$}

Small samples were machined out from these disks with the loading axis parallel to the tangential direction. Then the samples were solution heat-treated (SHT) at $\gamma^{\prime}$ sub-solvus temperature $1100^{\circ} \mathrm{C}$ or $1135^{\circ} \mathrm{C}$ for 4 hours. Two cooling rates during SHT, i.e. $230-270^{\circ} \mathrm{C} / \mathrm{min}$ (fast cooling: $\mathrm{FC}$ ) and $100-140^{\circ} \mathrm{C} / \mathrm{min}$ (slow cooling: SC), were chosen to simulate those of oil quenched commercial size disks. These cooling rates corresponded to rim and bore of a disk during oil quench, respectively. After SHT, aging treatment of 24 hours at $650^{\circ} \mathrm{C}$, followed by 16 hours at $760^{\circ} \mathrm{C}$ were carried out. The specimen identifications and heat treatment conditions are given in Table 2.

Table 2 Heat treatment condition

\begin{tabular}{|c|l|l|c|}
\hline \multirow{2}{*}{ Alloy } & \multicolumn{1}{|c|}{$\begin{array}{c}\text { Specimen } \\
\text { ID }\end{array}$} & SHT & Aging \\
\hline \multirow{4}{*}{$4 \mathrm{M} 3-\mathrm{I}$} & $4 \mathrm{M} 3-\mathrm{Ia}$ & $1100^{\circ} \mathrm{C} / 4 \mathrm{~h}, \mathrm{FC}$ & $650^{\circ} \mathrm{C}+760^{\circ} \mathrm{C}$ \\
& $4 \mathrm{M} 3-\mathrm{Ia}-\mathrm{SC}$ & $1100^{\circ} \mathrm{C} / 4 \mathrm{~h}, \mathrm{SC}$ & $650^{\circ} \mathrm{C}+760^{\circ} \mathrm{C}$ \\
\cline { 2 - 4 } & $4 \mathrm{M} 3-\mathrm{Ib}$ & $1135^{\circ} \mathrm{C} / 4 \mathrm{~h}, \mathrm{FC}$ & $650^{\circ} \mathrm{C}+760^{\circ} \mathrm{C}$ \\
& $4 \mathrm{M} 3-\mathrm{Ib}-\mathrm{SC}$ & $1135^{\circ} \mathrm{C} / 4 \mathrm{~h}, \mathrm{SC}$ & $650^{\circ} \mathrm{C}+760^{\circ} \mathrm{C}$ \\
\hline $4 \mathrm{M} 3-\mathrm{X}$ & $4 \mathrm{M} 3-\mathrm{X}$ & $1100^{\circ} \mathrm{C} / 4 \mathrm{~h}, \mathrm{FC}$ & $650^{\circ} \mathrm{C}+760^{\circ} \mathrm{C}$ \\
\hline \multirow{2}{*}{$720 \mathrm{Li}$} & $720 \mathrm{Li}$ & $1100^{\circ} \mathrm{C} / 4 \mathrm{~h}, \mathrm{FC}$ & $650^{\circ} \mathrm{C}+760^{\circ} \mathrm{C}$ \\
& $720 \mathrm{Li}-\mathrm{SC}$ & $1100^{\circ} \mathrm{C} / 4 \mathrm{~h}, \mathrm{SC}$ & $650^{\circ} \mathrm{C}+760^{\circ} \mathrm{C}$ \\
\hline
\end{tabular}

\section{Microstructures and mechanical testing}

The microstructures after heat treatment were observed by optical microscopy and scanning electron microscopy (SEM). These microstructures were characterized by electron backscatter diffraction (EBSD). The setting scan step size was $0.5 \mu \mathrm{m}$ in the EBSD measurements. Grain size and twin boundary $(\Sigma 3)$ were measured from EBSD data using a program TSL OIM analysis software.

Tensile strengths, creep resistances and fatigue strengths were examined. All mechanical testings were performed according to ASTM standards (tensile testing: ASTM E8/E21, creep testing: ASTM E139, LCF testing: ASTM E606).

\section{Results and Discussion}

Microstructures

The microstructures of these samples after heat-treatment consisted of $\gamma$ matrix and $\gamma^{\prime}$ precipitates with tri-modal distribution (primary, secondary and tertiary $\gamma^{\prime}$ ). Fig.2(a)-(d) show typical microstructures of 4M3-Ia, 4M3-Ib, 4M3-X and $720 \mathrm{Li}$, respectively. Each sample had fine grain $\gamma$ matrix with grain boundaries pinned by primary $\gamma^{\prime}$ precipitates $(0.5 \sim 4 \mu \mathrm{m})$ due to forging and heat-treatment below the $\gamma^{\prime}$ solvus temperature. Both of 4M3-Ia and 4M3-Ib had relatively uniform grains though inhomogeneous areas remained as shown in Fig.3(a)(b). These areas consisted of densely populated primary $\gamma^{\prime}$ and very fine grains less than $5 \mu \mathrm{m}[5]$.
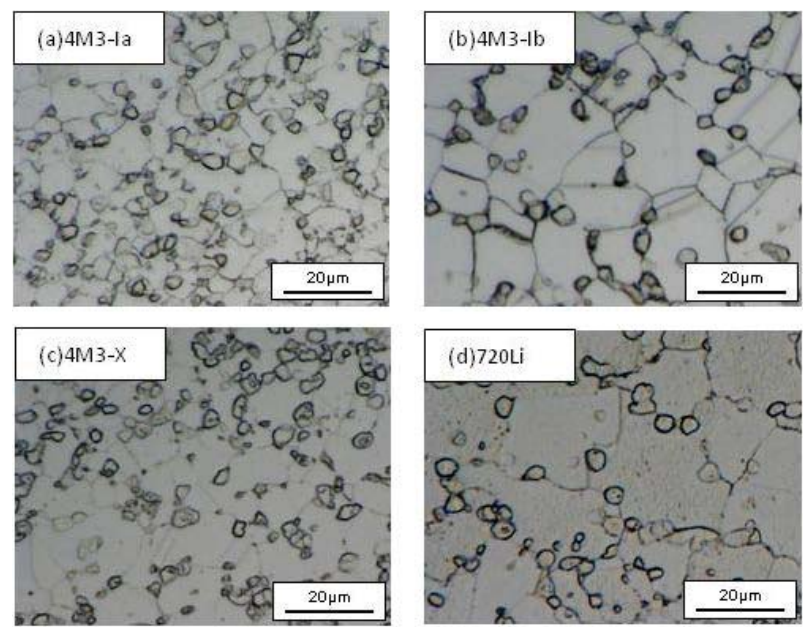

Fig.2 Typical microstructures after heat-treatment: (a)4M3-Ia, (b)4M3-Ib, (c)4M3-X, (d)720Li

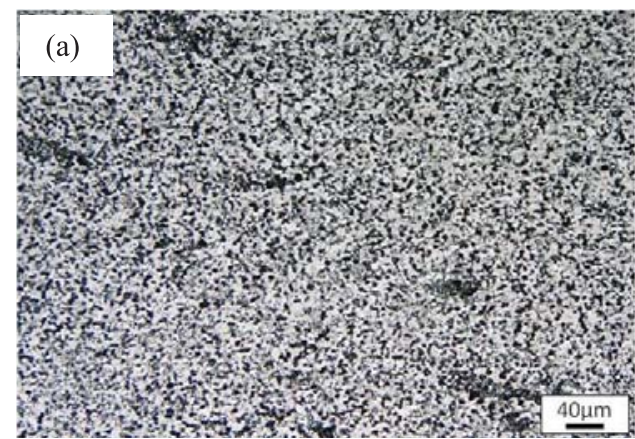

(a) low magnification

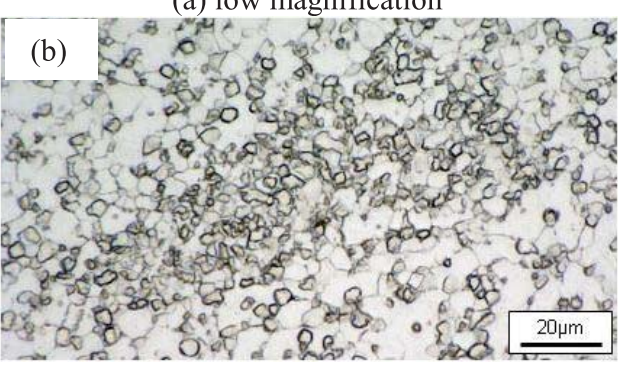

(b) high magnification

Fig.3 Inhomogeneous primary $\gamma^{\prime}$ area of 4M3-Ia, (a) low magnification and (b) high magnification 
EBSD images of $4 \mathrm{M} 3-\mathrm{Ia}, 4 \mathrm{M} 3-\mathrm{X}$ and $720 \mathrm{Li}$ are shown in Fig.4(a)-(c). These measured areas were typical homogeneous regions of each alloy.

4M3-Ia had uniform recrystallized microstructure which consisted of fine grains and primary $\gamma^{\prime}$. Average grain size and as large as (ALA) grain size of 4M3-Ia were about $5-7 \mu \mathrm{m}$ and $20 \mu \mathrm{m}$. On the other hand, 4M3-X had non-uniform microstructure which consisted of very fine grains (less than $5 \mu \mathrm{m}$ ) and relatively large grains $(10-30 \mu \mathrm{m})$. Average grain size of $4 \mathrm{M} 3-\mathrm{X}$ was the same as that of 4M3-Ia. However, ALA grain size of 4M3-X was larger than that of 4M3-Ia due to non-uniformity of $\gamma$ matrix. 720 Li had uniform microstructure which consisted of relatively large $\gamma$ matrix grains $(9-14 \mu \mathrm{m})$ and primary $\gamma^{\prime}$ particles.

Fig.5(a)(b)(c) are inhomogeneous areas of 4M3-Ia, 4M3-X and $720 \mathrm{Li}$, respectively. Each alloy had non-uniform grains consisted of fine grains and primary $\gamma^{\prime}$. These are caused by densely populated primary $\gamma^{\prime}$. 4M3-Ia had less un-recrystallized grains (UNRX) compared to other alloys. 4M3-X and 720Li had some UNRX in inhomogeneous areas.



(b) Homogeneous area of 4M3-X

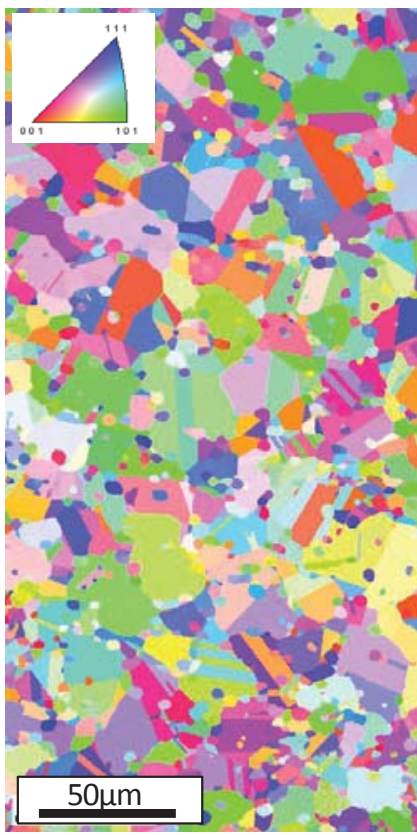

(c) Homogeneous area of $720 \mathrm{Li}$

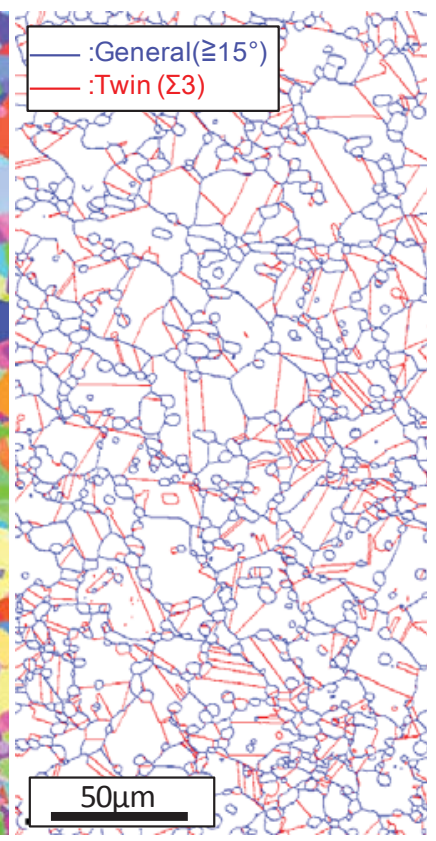

(a) Homogeneous area of 4M3-Ia

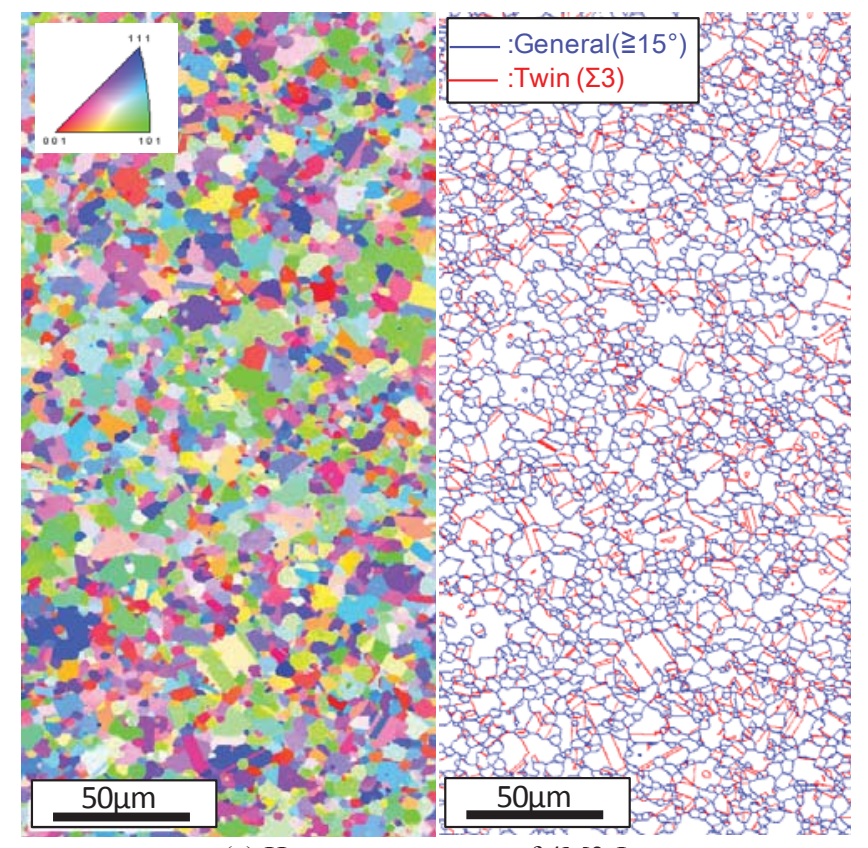

Fig.4 EBSD images (Left: IPF image, Right :GB map) of each alloy: (a)4M3-Ia, (b)4M3-X and (c)720Li

(blue lines: general grain boundary $\geqq 15^{\circ}$, red lines: twin boundary $\Sigma 3$ ) 


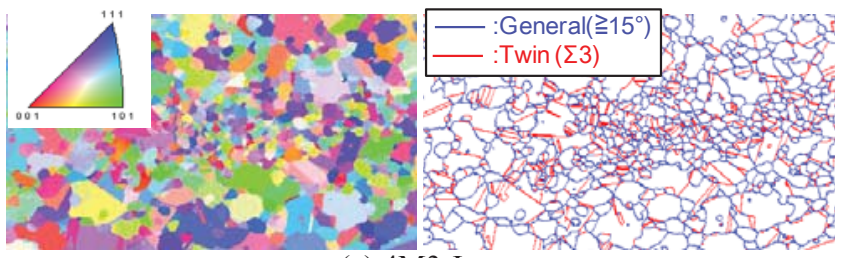

(a) $4 \mathrm{M} 3-\mathrm{Ia}$

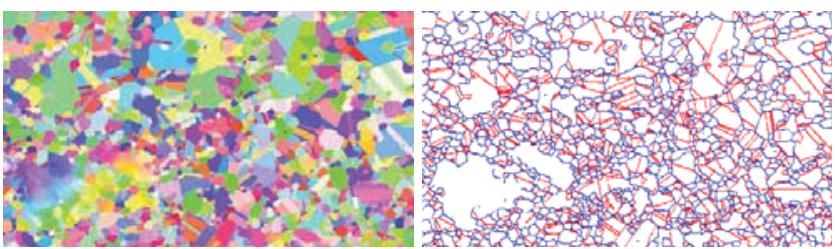

(b) $4 \mathrm{M} 3-\mathrm{X}$
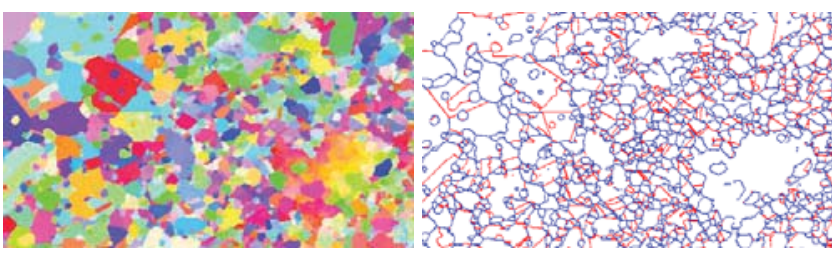

(c) $720 \mathrm{Li}$

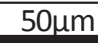

Fig.5 EBSD images of inhomogeneous areas (Left: IPF image, Right: GB map) of each alloy:

(a) 4M3-Ia, (b)4M3-X and (c)720Li

(blue lines: general grain boundary $\geqq 15^{\circ}$, red lines: twin boundary $\Sigma 3$ ).

Table 3 gives the grain sizes and the primary $\gamma^{\prime}$ volume fraction of each sample. The distributions of $\gamma$ matrix grain sizes which were calculated by EBSD analysis of each sample are shown in Fig.6. Average grain sizes of $4 \mathrm{M} 3-\mathrm{Ia}$ and $4 \mathrm{M} 3-\mathrm{X}$ were similar and smaller than those of 4M3-Ib and 720Li. 4M3-Ia had small ALA grain size and less UNRX area fraction compared to 4M3-X. Average grain size of $4 \mathrm{M} 3-\mathrm{Ib}$ treated at higher SHT temperature became larger than those of $4 \mathrm{M} 3-\mathrm{Ia}$ and $720 \mathrm{Li}$ because of decreasing primary $\gamma^{\prime}$. However, it is noted that ALA grain size of 4M3-Ib was close to that of 720Li regardless of low primary $\gamma^{\prime}$ volume fraction. These results indicate that $4 \mathrm{M} 3-\mathrm{Ia}$ and $4 \mathrm{M} 3-\mathrm{Ib}$ had homogenous microstructures compared to $4 \mathrm{M} 3-\mathrm{X}$ and $720 \mathrm{Li}$.

Table 3 Microstructure of each alloy

\begin{tabular}{|c|c|c|c|c|c|}
\hline Alloy & $\begin{array}{c}\text { SHT } \\
\mathrm{T}^{\circ} \mathrm{C} \times 4 \mathrm{~h}\end{array}$ & $\begin{array}{c}\text { Primary } \gamma^{\prime} \\
\text { Vf }(\%)\end{array}$ & $\begin{array}{c}\text { Ave.GS } \\
(\mu \mathrm{m})\end{array}$ & $\begin{array}{c}\text { ALA GS } \\
(\mu \mathrm{m})\end{array}$ & $\begin{array}{c}\text { UNRX } \\
\text { Af }(\%)\end{array}$ \\
\hline 4M3-Ia & 1100 & 20 & 6.0 & 20.5 & $<0.1$ \\
\hline 4M3-Ib & 1135 & 13 & 13.2 & 46.8 & $<0.1$ \\
\hline 4M3-X & 1100 & 19 & 5.8 & 31.9 & 2.3 \\
\hline $720 \mathrm{Li}$ & 1100 & 15 & 11.7 & 43.4 & 0.4 \\
\hline
\end{tabular}

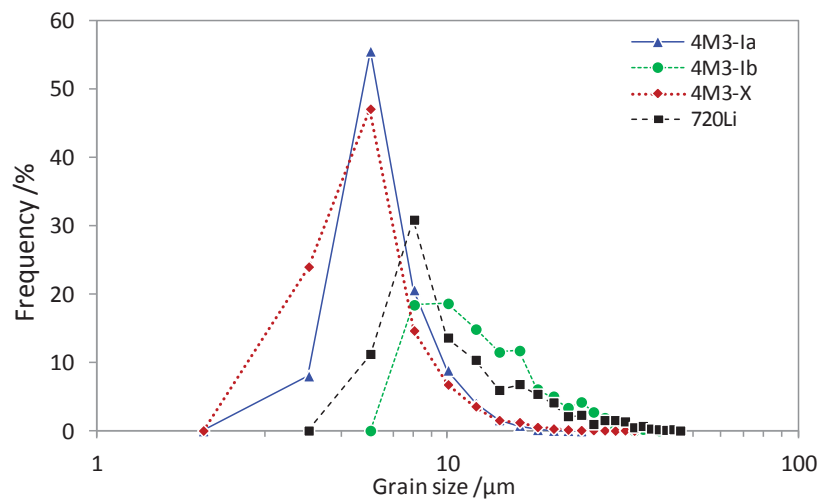

Fig.6 Distribution of grain size excluding $\Sigma 3$ twin boundary and primary $\gamma^{\prime}$ particles 


\section{$\underline{\text { Intragranular } \gamma^{\prime} \text { precipitation }}$}

Fig. 7 and Table 4 show distributions of intragranular (secondary and tertiary) $\gamma^{\prime}$ precipitates. Average sizes of these intragranular $\gamma^{\prime}$ seem to be similar to those of oil-quenched disks [1].

The size and volume fraction of secondary $\gamma^{\prime}$ of these samples were dependent on SHT temperature and following cooling rate. Secondary $\gamma^{\prime}$ size depended on SHT cooling rate. It is thought that the higher cooling rate results in more undercooling and increasing $\gamma^{\prime}$ nucleation sites. Secondary $\gamma^{\prime}$ volume fraction depended on SHT temperature. This is caused by the difference in solid-soluted primary $\gamma^{\prime}$ during SHT temperature. Differences in distribution of tertiary $\gamma^{\prime}$ of each sample were not clear though 4M3-Ib had slightly higher volume fraction. 4M3-Ia, 4M3-X and $720 \mathrm{Li}$ at same cooling rates had nearly identical distribution of intragranular $\gamma^{\prime}$.
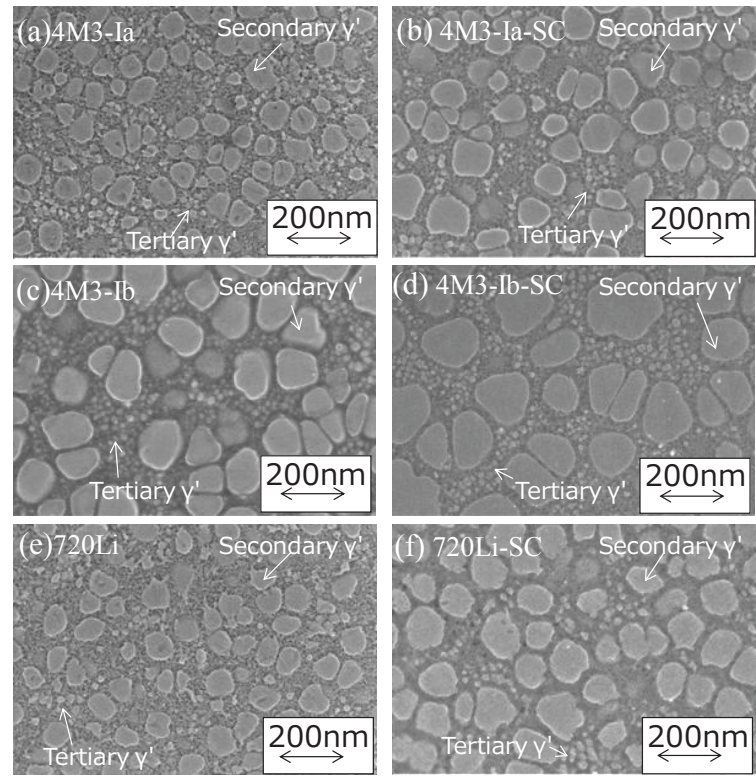

Fig.7 SEM images of intragranular $\gamma^{\prime}$ precipitation of each sample (a)4M3-Ia, (b)4M3-Ia-SC, (c)4M3-Ib, (d) 4M3-Ib-SC,

(e) $720 \mathrm{Li},(\mathrm{f}) 720 \mathrm{Li}-\mathrm{SC}$

Table $4 \gamma^{\prime}$ precipitation of each sample

\begin{tabular}{|l|c|c|c|c|c|}
\hline $\begin{array}{l}\text { Specimen } \\
\text { Identification }\end{array}$ & $\begin{array}{c}\text { Primary } \\
\gamma^{\prime}\end{array}$ & \multicolumn{2}{|c|}{$\begin{array}{c}\text { Secondary } \\
\gamma^{\prime}\end{array}$} & \multicolumn{2}{|c|}{$\begin{array}{c}\text { Tertiary } \\
\gamma^{\prime}\end{array}$} \\
\cline { 3 - 6 } & $\begin{array}{c}\text { Vf } \\
(\%)\end{array}$ & $\begin{array}{c}\text { Vf } \\
(\%)\end{array}$ & $\begin{array}{c}\mathrm{d} \\
(\mathrm{nm})\end{array}$ & $\begin{array}{c}\mathrm{Vf} \\
(\%)\end{array}$ & $\begin{array}{c}\mathrm{d} \\
(\mathrm{nm})\end{array}$ \\
\hline 4M3-Ia & \multirow{2}{*}{20} & 26 & 62 & $\sim 3$ & $\sim 15$ \\
\cline { 1 - 4 } 4M3-Ia-SC & 26 & 74 & $\sim 3$ & $\sim 15$ \\
\hline 4M3-Ib & \multirow{2}{*}{13} & 33 & 88 & $\sim 4$ & $\sim 15$ \\
\cline { 1 - 4 } 4M3-Ib-SC & & 33 & 114 & $\sim 4$ & $\sim 15$ \\
\hline 4M3-X & 19 & 28 & 59 & $\sim 3$ & $\sim 15$ \\
\hline 720Li & \multirow{2}{*}{15} & 26 & 66 & $\sim 3$ & $\sim 15$ \\
\hline 720Li-SC & 15 & 27 & 77 & $\sim 3$ & $\sim 15$ \\
\hline
\end{tabular}

\section{Tensile properties}

Tensile tests were performed in the range of room temperature to $760^{\circ} \mathrm{C}$ (Fig.8(a)(b)(c)). $0.2 \%$ YS and UTS of 4M3-Ia were similar to those of $4 \mathrm{M} 3-\mathrm{X}$ in the entire range of testing temperatures. $0.2 \% \mathrm{YS}$ and UTS of $4 \mathrm{M} 3-\mathrm{Ib}$ were also comparable to those of 4M3-Ia and 4M3-X although they were slightly lower below $400^{\circ} \mathrm{C}$ and higher beyond $650^{\circ} \mathrm{C}$. The tensile strengths of these TMW-4M3 were about 50-100MPa higher than those of $720 \mathrm{Li}$.
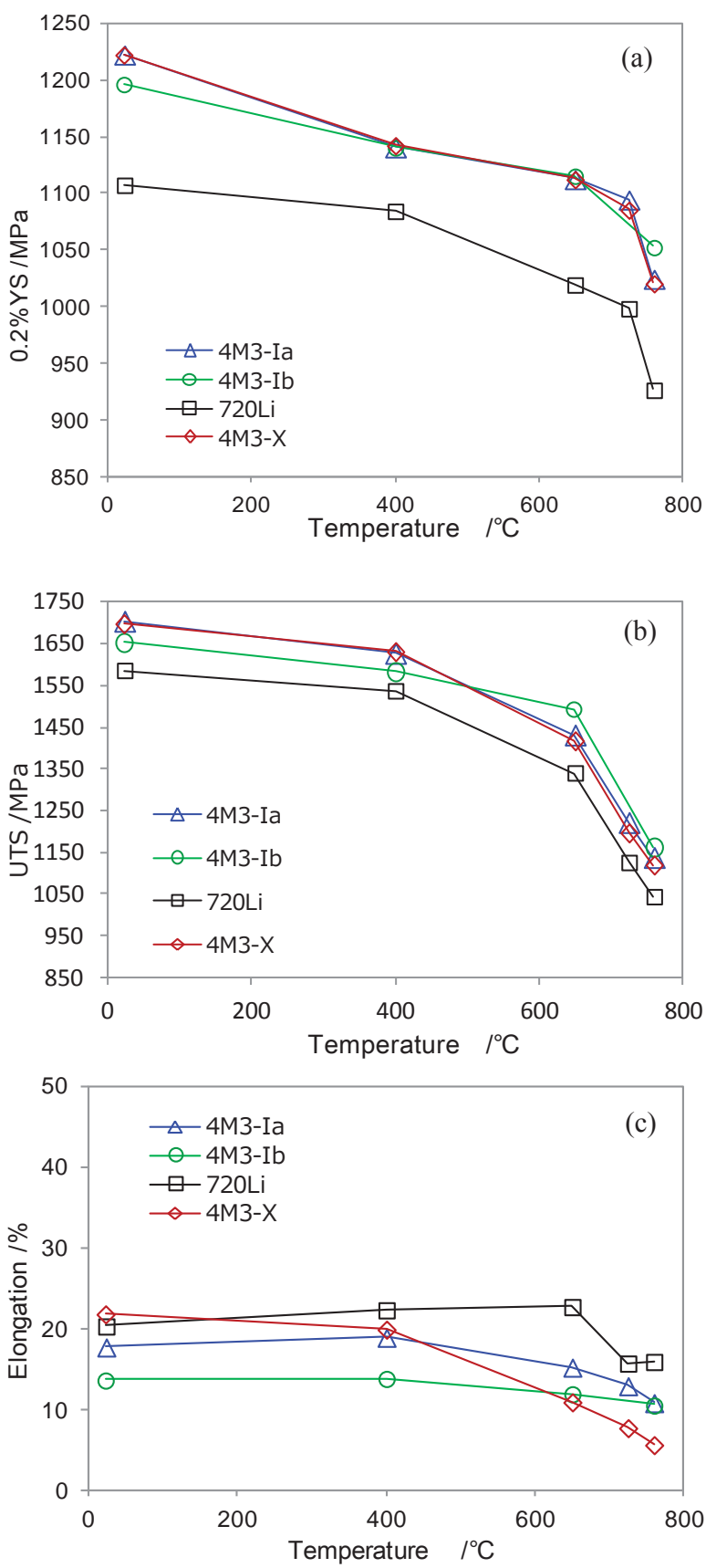

Fig. 8 Tensile properties (a) $0.2 \%$ YS, (b)UTS, (c)EL 


\section{$\underline{\text { Creep properties }}$}

Creep rupture tests were performed at $725^{\circ} \mathrm{C}$ under 840 to $480 \mathrm{MPa}$ stresses. The creep curves, the creep properties under $630 \mathrm{MPa}$ and the Larson-Miller-Parameter of creep rupture life are shown in Fig.9(a)(b)(c), respectively. 4M3-Ia and 4M3-X had much longer rupture life compared to $720 \mathrm{Li}$ despite finer matrix grains and identical distribution of intragranular $\gamma^{\prime}$.

Comparing 4M3-Ia and 4M3-X, both creep rupture life and rupture elongation of 4M3-Ia could be improved. These are probably attributed to increasing amount of $\mathrm{Ti}, \mathrm{B}$ and $\mathrm{Zr}$ because they had identical average grain sizes and intragranular $\gamma^{\prime}$ sizes. Generally, Ti is widely accepted as $\gamma^{\prime}$ strengthener and $\mathrm{B} / \mathrm{Zr}$ are assumed to segregate to grain boundaries as grain-boundary strengtheners. Although the each contribution of $\mathrm{Ti}, \mathrm{B}$ and $\mathrm{Zr}$ to the creep properties is not clear quantitatively, however, it is obvious that 4M3-Ia had good creep and tensile ductility above $650^{\circ} \mathrm{C}$ compared to $4 \mathrm{M} 3-\mathrm{X}$ as shown in Fig.8(c) and Fig.9(a)(b). Therefore, it can be inferred that B and/or Zr which can play as the grain boundary strengtheners enhanced the creep properties of TMW-4M3.

Comparing 4M3-Ia-SC and 4M3-X, this advantage of chemical compositions was maintained in case of decreasing SHT cooling rate although creep resistance, especially $1 \%$ creep life, slightly decreased. These results indicate that by increasing strength elements, $\mathrm{Ti}, \mathrm{B}$ and $\mathrm{Zr}$, it is possible to improve the creep properties of TMW-4M3.

In addition, 4M3-Ib treated at higher SHT temperature exhibited a high creep resistance under $480 \sim 630 \mathrm{MPa}$ compared with $4 \mathrm{M} 3-\mathrm{Ia}$. It is thought that this improvement is attributed to larger grain size and increasing amount of intragranular $\gamma^{\prime}$. 4M3-Ib could maintain good creep ductility regardless of larger grain. This reason is probably associated with $\mathrm{B}$ and/or $\mathrm{Zr}$ which can improve strengthening of grain boundary. Rupture life of $4 \mathrm{M} 3-\mathrm{Ib}$ and 4M3-Ib-SC were comparable with ME3 which is produced by powder metallurgy route[6].
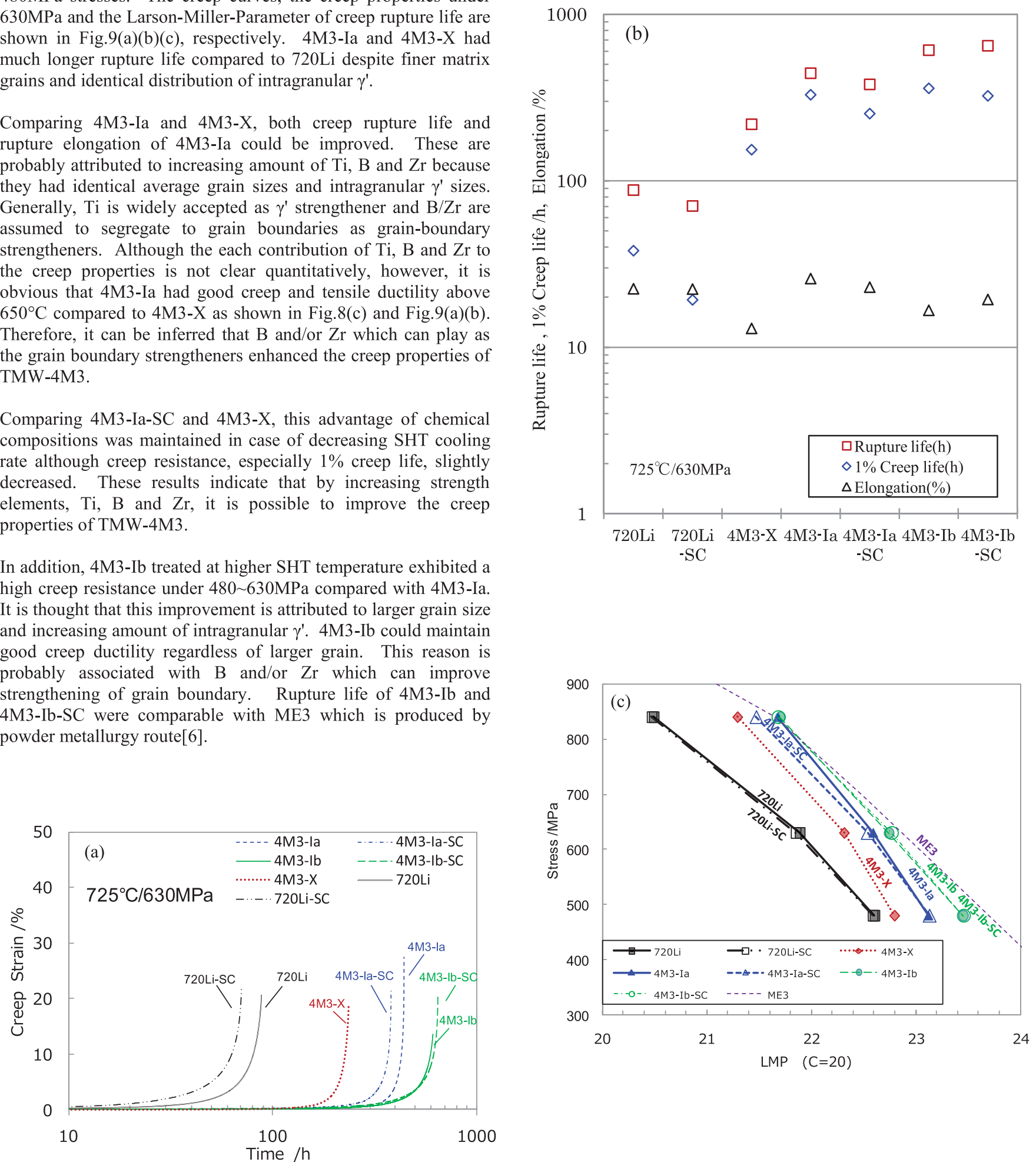

Fig.9 Creep properties of each alloy (a) creep curve, (b) rupture life, 1\% creep life and elongation,

(c) Larson Miller Parameter (LMP) of creep rupture life $(\mathrm{C}=20)$ 


\section{Low cycle fatigue properties}

LCF tests in air environment were conducted at $400^{\circ} \mathrm{C}$ and $650^{\circ} \mathrm{C}$ under strain controlled condition $(\mathrm{R}=0,0.5 \mathrm{~Hz})$ in the range of $\Delta \varepsilon_{t}=0.8-1.2 \%$. The tests were carried out on smooth cylindrical specimens with a diameter of $6.35 \mathrm{~mm}$ and a gauge length of 19 $\mathrm{mm}$.

Fatigue properties at $400^{\circ} \mathrm{C}$ are shown in Fig.10. Fatigue life at $400^{\circ} \mathrm{C}$ of $4 \mathrm{M} 3$-Ia was longer than that of $4 \mathrm{M} 3-\mathrm{X}$ although tensile properties at same temperature were similar. Fatigue life of 4M3$\mathrm{Ib}$ was similar to that of $720 \mathrm{Li}$. Relationship between grain size and number of cycles to failure (Nf) at $400^{\circ} \mathrm{C}$ under $\Delta \varepsilon_{\mathrm{t}}=0.8 \%$ is shown in Fig.11. It is obvious that $\mathrm{Nf}$ depended on ALA grain size. 4M3-Ia having smaller ALA grain exhibited higher fatigue strength.

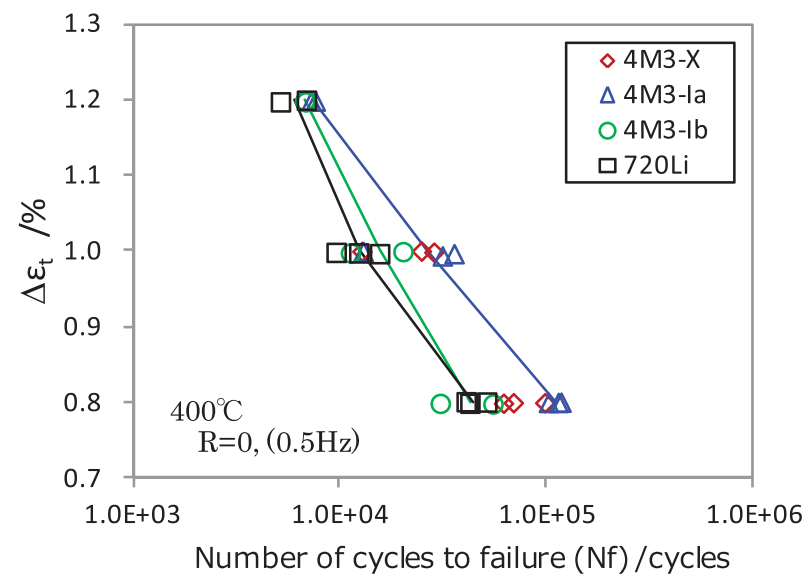

Fig.10 Fatigue life at $400^{\circ} \mathrm{C}$

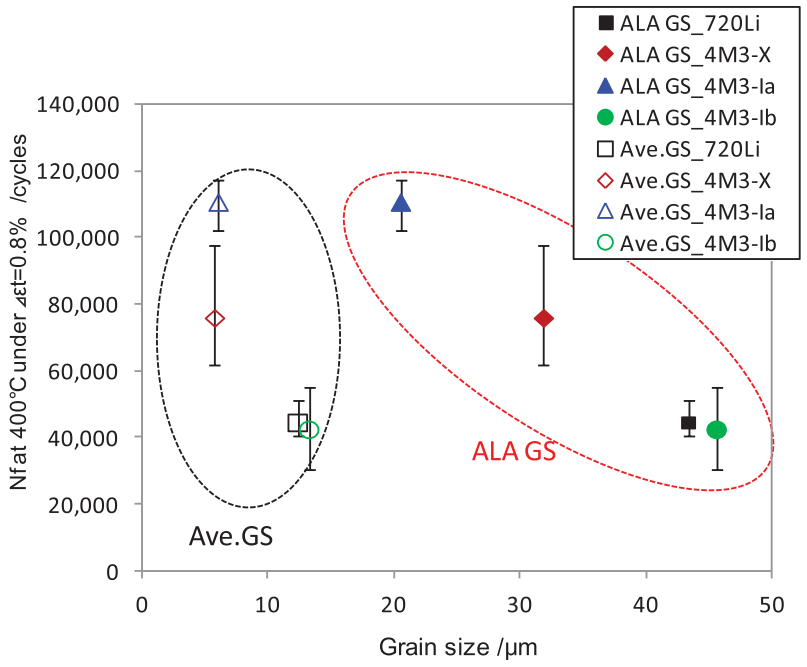

Fig.11 Relationship between grain size and number of failure $\left(400^{\circ} \mathrm{C}, \Delta \varepsilon_{\mathrm{t}}=0.8 \%\right)$

The fracture surfaces of tested specimens $\left(400^{\circ} \mathrm{C} / 0.8 \%\right)$ were observed by SEM. The crack initiation sites were mostly the facets with crystallographic features as shown in Fig.12. In
TMW-4M3 disks reported by Z. Zhong, et al.[7], grain fracture surfaces after LCF testing in this condition were also observed. The size of facet at the crack initiation of each failed specimen was measured from SEM images. Relationship between grain size and facet size are shown in Fig.13. It seem that the sizes of these facets tended to correspond not to average grain size but to ALA grain size $[8,9]$. 4M3-Ia had small facets compared with $4 \mathrm{M} 3-\mathrm{X}$ though they had similar average grain sizes. The facet sizes of $4 \mathrm{M} 3-\mathrm{Ib}$ and $720 \mathrm{Li}$ having similar ALA grain size were nearly identical. Therefore, one of the main reasons for differences in fatigue lives at $400^{\circ} \mathrm{C} / 0.8 \%$ is caused by ALA grain size. These results indicate that uniform grains of TMW-4M3 disk via improved processes gave good fatigue life compared with another TMW-4M3 disk and a commercial Alloy 720Li disk.

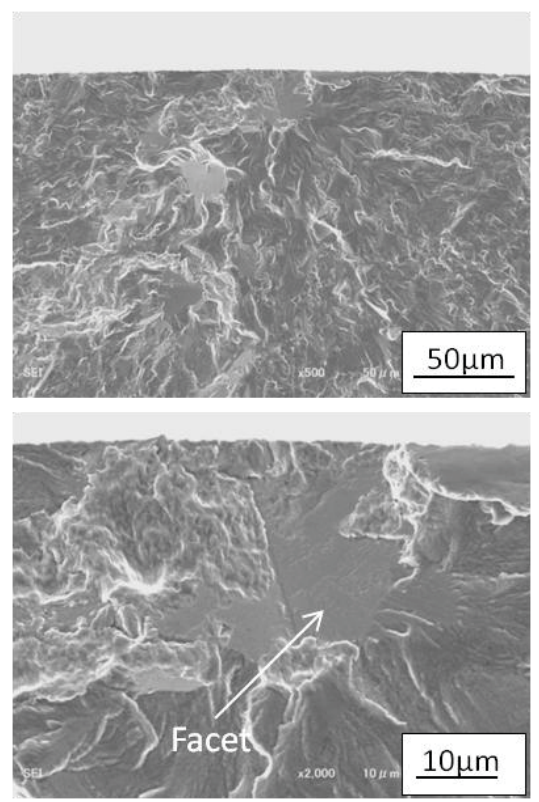

Fig.12 Fracture surface of failed specimen $\left(4 \mathrm{M} 3-\mathrm{Ib}, 400^{\circ} \mathrm{C} / 0.8 \%, \mathrm{Nf}=54,940\right)$

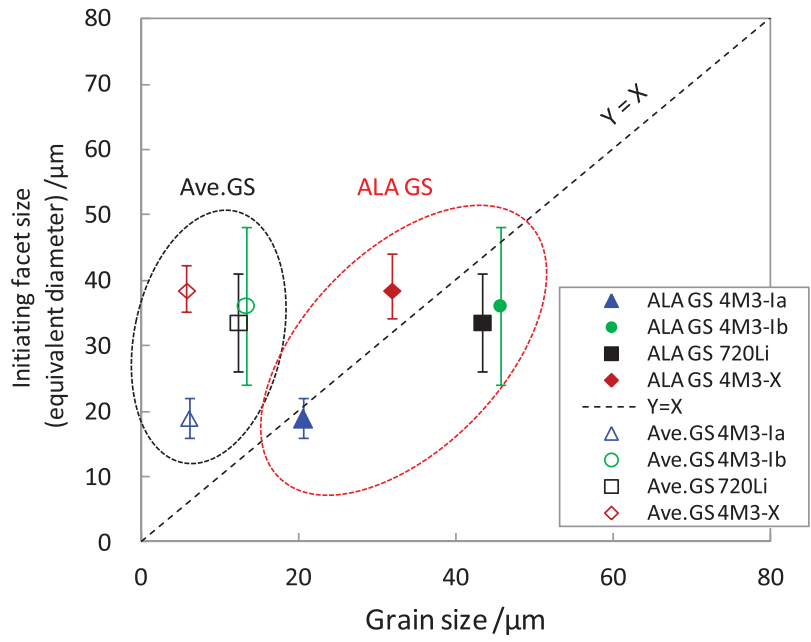

Fig.13 Relationship between facet size and grain size 
Second, results of LCF testing at $650^{\circ} \mathrm{C}$ are shown in Fig. 14 . Fatigue life at $650^{\circ} \mathrm{C}$ under $\Delta \varepsilon_{\mathrm{t}}=0.8-1.0 \%$ of $4 \mathrm{M} 3-\mathrm{Ia}$ was close to that of $4 \mathrm{M} 3-\mathrm{Ib}$. These fatigue lives were longer than that of $720 \mathrm{Li}$ Influence of grain size on fatigue life at $650^{\circ} \mathrm{C}$ was not clear unlike the case of $400^{\circ} \mathrm{C}$. In this testing condition, $4 \mathrm{M} 3-\mathrm{Ib}$ having large grain size and high creep resistance exhibited good fatigue strength compared to $720 \mathrm{Li}$.

All specimens after testing were observed by SEM. Faceted grain was not observed. Initiation sites were blocky titanium carbide or particle clusters which mainly contained high contents of titanium and carbon by EDX [7]. These initiation sites are shown in Fig. 15 (a)(b). It is thought that the influence of grain size is reduced for the case where inclusions dominate fatigue.

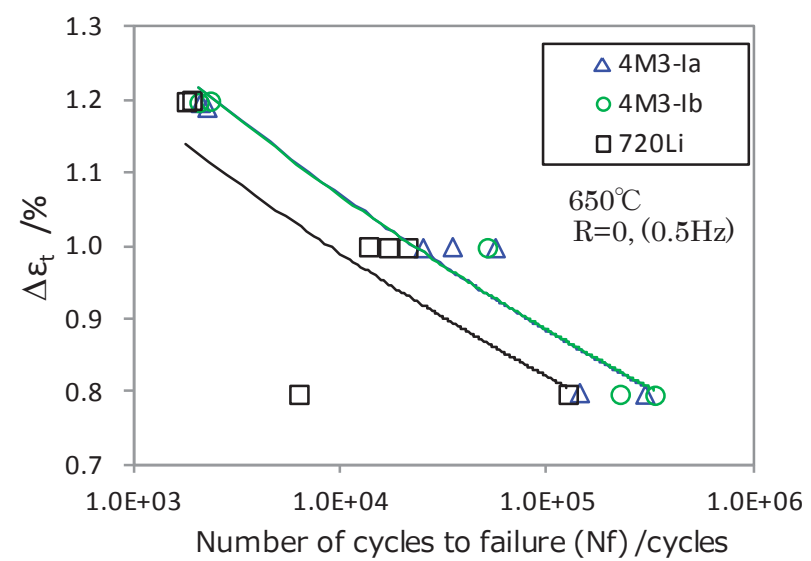

Fig. 14 Fatigue life at $650^{\circ} \mathrm{C}$
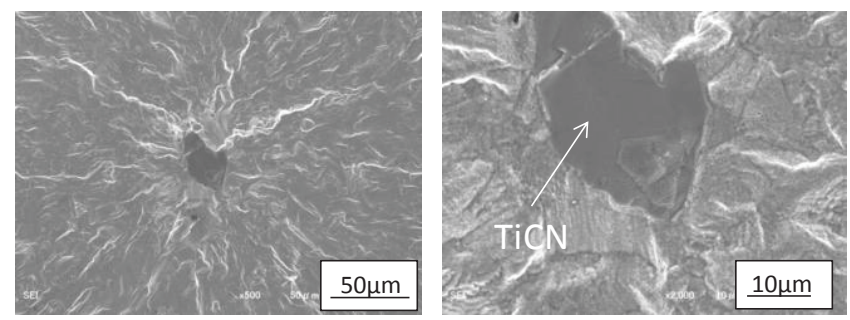

(a)blocky inclusion failure initiating

$\left(4 \mathrm{M} 3-\mathrm{Ib}, 650^{\circ} \mathrm{C} / 0.8 \%, \mathrm{Nf}=225,670\right)$
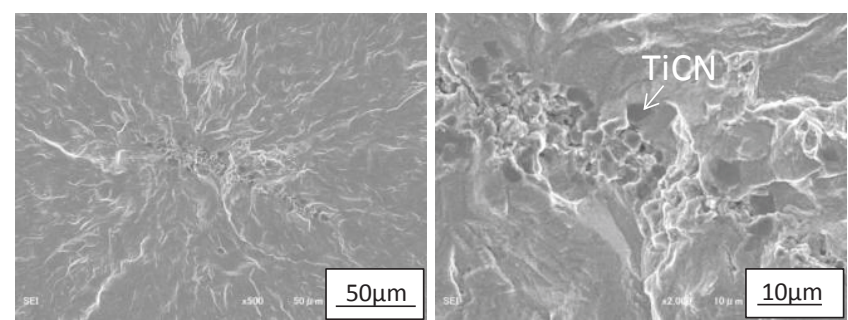

(b)inclusion cluster failure initiating $\left(4 \mathrm{M} 3-\mathrm{Ib}, 650^{\circ} \mathrm{C} / 0.8 \%, \mathrm{Nf}=332,589\right)$

Fig.15 Fracture surfaces of failed specimens

\section{Conclusion}

A TMW-4M3 pancake disk with increasing amounts of strengthening elements ( $\mathrm{Ti}, \mathrm{B}$ and $\mathrm{Zr}$ ) was produced via improved hot-working process. Microstructure and mechanical properties of this disk were investigated comparing to a previous trial TMW-4M3 disk and an Alloy 720Li disk. The previous trial TMW-4M3 disk was produced via earlier less-optimal process from a standard composition ingot. These disks were solution heat-treated at $\gamma^{\prime}$ sub-solvus temperature and same aging condition. These results are summarized as follows.

1) A TMW-4M3 disk via improved process had fine grains pinned by primary $\gamma^{\prime}$ particles after solution heat-treated at $1100^{\circ} \mathrm{C}$. ALA grain size of this microstructure was finer than that of previous trial microstructure via not optimal process, though average grain sizes were similar.

2) Creep rupture life at $725^{\circ} \mathrm{C}$ of TMW-4M3 having larger amounts of $\mathrm{Ti}, \mathrm{B}$ and $\mathrm{Zr}$ was higher than that of standard composition.

3) Fatigue life at $400^{\circ} \mathrm{C}$ under $\Delta \varepsilon_{\mathrm{t}}=0.8 \%$ depended on ALA grain size. A TMW-4M3 disk via improved process had long fatigue life compared to other disks due to small ALA grain size.

4) Fatigue lives at $650^{\circ} \mathrm{C}$ of TMW-4M3 heat-treated at different solution heat temperatures, i.e. $1100^{\circ} \mathrm{C}$ and $1135^{\circ} \mathrm{C}$, were similar, and better than that of Alloy 720Li.

5) These results indicate that a TMW-4M3 disk having larger amounts of strengthening elements ( $\mathrm{Ti}, \mathrm{B}$ and $\mathrm{Zr}$ ) via improved billeting process could be obtain good creep resistance and fatigue strength.

\section{References}

1. Y.F.Gu, et al., "An Advanced Cast-and-Wrought Superalloy (TMW-4M3) for Turbine Disk Applications Beyond $700^{\circ} \mathrm{C}$, Superalloys 2012, ed. Eric S. Huron, et al., (Warrendale, PA, USA: TMS, 2012), 903-910

2. Y.F. Gu, et al., "Development of Ni-Co base alloys for hightemperature disk applications", Superalloys 2008, ed. R.C. Reed et al., (Warrendale, PA, USA: TMS, 2008), 53-61

3. Z. Zhong, et al., "Effect of Solution Temperature on the Microstructure and Mechanical Properties of a Newly Developed Superalloy TMW-4M3", Metallurgical and Materials Transactions A, Vol.43A, (2012), 1017-1025

4. Roger C. Reed, The Superalloys Fundamental and Applications, Cambridge University Press, (2006), 217-242

5. Joseph A. Heaney, et al., "Development of a New Cast and Wrought Alloy (RENE 65) for High Temperature Disk Applications", 8th International Symposium on Superalloy 718 
and Derivatives, ed. Eric Ott, et al., (Warrendale, PA, USA: TMS, 2014), 67-77.

6. Timothy P. Gabb et al., "Characterization of the Temperature Capabilities of Advanced Disk Alloy ME3," (Report NASA TM 2002-211796, August 2002)

7. Z. Zhong, et al., "Mechanical properties and fracture modes of an advanced Ni-Co-base disk superalloy at elevated temperatures", Materials Characterization 67, (2012), 101-111

8. Jiashi Miao, T. M. Pollock, J. W. Jones, "Fatigue Crack Initiation in Nickel-based Superalloy René 88 DT at $593^{\circ} \mathrm{C}$, Superalloys 2008, ed. Roger C. Reed et al., (Warrendale, PA, USA: TMS, 2008), 589-597

9. Mandy L. Brogdon, Andrew H. Rosenberger, "Evaluation of the Influence of Grain Structure on the Fatigue Variability of Waspaloy", Superalloys 2008, ed. Roger C. Reed et al., (Warrendale, PA, USA: TMS, 2008), 583-588 